\title{
Association between DLA-DRB1.2 allelic diversity and development of mammary gland tumors in dogs
}

\author{
Seyed Milad Vahedi ${ }^{1}$, Gholamreza Nikbakht ${ }^{{ }^{*}}$ (i), Shahram Jamshidi ${ }^{2}$, Leila Lankarani ${ }^{1}$, Nika Alimi ${ }^{1}$ \\ and Atefeh Esmailnejad ${ }^{3}$
}

\begin{abstract}
Background: The major histocompatibility complex (MHC) is the best-characterized genetic region related to resistance/susceptibility to a wide range of infectious and immune-mediated diseases. Evidences suggest that MHC class II genes may play an important role in developing different types of tumors including breast cancer. Canine mammary gland tumors (CMTs) are the most common neoplasms in female dogs. In the current study, the association of canine MHC class II DLA-DRB1.2 genotypes with development of mammary gland tumor profiles in dogs was investigated. DLA-DRB1.2 allelic diversity was determined in 40 dogs (18 CMT cases and 22 controls) using HRM technique and DNA sequencing. Association of the DLA-DRB1.2 genotypes with CMT profiles was expressed as odds ratio (OR).
\end{abstract}

Results: Based on the histopathological typing of tumors, CMT cases were categorized into 4 groups: simple carcinoma, complex carcinoma, carcinoma arising in a benign tumor and special types of carcinoma. A total of eight HRM profiles ( $\mathrm{A}$ to $\mathrm{H}$ ) were identified in dogs sampled. The association study revealed a significant correlation between DLA-DRB1.2 genotypes with different CMT profiles. The E genotype was significantly associated with increased risk of carcinoma arising in a benign tumor, and the B genotype represented a positive correlation with complex carcinoma. Significant association was also observed between the heterozygosity of DLA-DRB1.2 genotypes and decreased risk of developing tumor in dogs.

Conclusions: These results provide additional support for the association between DLA-DRB1 genes and development of mammary gland tumors in dogs and could potentially be used for early diagnosis of neoplasia and identifying susceptible dogs.

Keywords: Canine mammary gland tumors, MHC, DLA-DRB1.2, Dog

\section{Background}

Canine mammary gland tumors (CMTs) are considered as the most common neoplasm in female dogs. The majority of malignant mammary gland tumors in dogs are carcinomas, while sarcomas account for 5\% [1]. Different factors are involved in development of mammary neoplasms including age, breed and genetic predisposition, hormones and growth factors, cyclooxygenase-2 expression, and diet [2]. Among these, the role of the

\footnotetext{
*Correspondence: nikbakht@ut.ac.ir

${ }^{1}$ Department of Microbiology and Immunology, Faculty of Veterinary

Medicine, University of Tehran, Tehran, Islamic Republic of Iran

Full list of author information is available at the end of the article
}

genetic background in conferring the increased risk of developing mammary gland tumors is quite prominent [3].

The major histocompatibility complex (MHC) is a cluster of genes associated with immune responses to infectious diseases and immune-mediated disorders. MHC allele products bind to intracellular and extracellular antigens and present them to $\mathrm{T}$ cells to induce an effective immune response. The canine $\mathrm{MHC}$, also known as dog leukocyte antigen (DLA), is composed of three clusters of genes, including class I, II and III genes [4]. DLAclass I and II molecules are responsible for presenting of self and non-self antigens to the immune system and 
regulating the immune responses [5]. DLA-class II region includes four loci DRA, DRB1, DQA1 and DQB1. Kennedy et al. [6] identified 90 DLA-DRB1, 22 DLA-DQA1 and 54 DLA-DQB1 alleles in the dog. The MHC class II alleles have been associated with a wide range of immune and non-immune responses in humans and animals and considered as a genetic risk factor for many autoimmune diseases [7]. It has been demonstrated that susceptibility and resistance to diseases, such as chronic superficial keratitis (CKS), hypoadrenocorticism and Greyhound meningoencephalitis are associated with the MHC class II alleles [8-10].

A strong association between MHC class II alleles and risk of developing different types of tumors has been reported in humans. Previous studies demonstrated the role of the HLA-DRB1 locus in genetic susceptibility to colorectal carcinoma, cervical cancer, acute leukemia, melanoma, renal cell carcinoma, and breast cancer [1116]. Several other studies conducted in humans have also showed that some HLA-DRB1 genotypes may increase or decrease the risk of breast cancer [12, 17-19]. In spite of several studies on the association between DRB1 genotypes and breast cancer in human, to the best of our knowledge, there is no information regarding the MHC genotypes and CMTs. In this study, DLA-DRB1 genetic polymorphism was evaluated in a dog population. Subsequently, the association of MHC genotypes with mammary gland tumor profiles was analyzed.

\section{Methods}

\section{Sample collection}

This study was conducted prospectively on 18 bitches of six breeds with malignant CMTs referred to the Small Animal Teaching Hospital of University of Tehran, Iran, between 2012 and October 2017. A total of 22 breed and age-matched healthy bitches was considered as control group (Table 1). Tumors classification was carried out according to the World Health Organization's criteria for histologic typing of CMTs [20]. The examined CMTs consisted of 8 (44.5\%) complex carcinoma, 4 (22.2\%) simple carcinoma, $4(22.2 \%)$ carcinoma arising in a benign tumor and 2 (11.1\%) special types of carcinoma. Blood samples from control dogs were collected in microtubes containing EDTA under sterile conditions and stored at $-20{ }^{\circ} \mathrm{C}$ until further analysis. The study was approved by Institutional Ethical Committee of University of Tehran, Tehran, Iran.

\section{Genomic DNA extraction}

DNA extraction from dogs of the tumor group was achieved using paraffin embedded blocks. Sections of paraffin embedded blocks were deparaffinized in
Table 1 Demographic characteristics of canine mammary tumor (CMT) cases and healthy control groups

\begin{tabular}{|c|c|c|c|}
\hline & CMT $(n=18)$ & Controls $(n=22)$ & P-value \\
\hline Age (years) & 7.50 & 7.50 & - \\
\hline \multicolumn{4}{|l|}{ Breed } \\
\hline Terrier & $9(50.0 \%)$ & $10(45.5 \%)$ & 0.512 \\
\hline Shih Tzu & $4(22.2 \%)$ & $5(22.7 \%)$ & 0.503 \\
\hline German Shepherd & $2(11.1 \%)$ & $2(9.1 \%)$ & 0.617 \\
\hline Great Dane & $1(5.6 \%)$ & $1(4.5 \%)$ & 0.450 \\
\hline Pekingese & $1(5.6 \%)$ & $3(13.6 \%)$ & 0.558 \\
\hline Chihuahua & $1(5.6 \%)$ & $1(4.5 \%)$ & 0.450 \\
\hline
\end{tabular}

xylene, $100 \%$ ethanol, $96 \%$ ethanol and $70 \%$ ethanol. DNA extraction of deparaffinized tissue was performed according to the instruction of extraction kit (Tissue DNA extraction kit, MBST, Iran). Genomic DNA from control group blood samples was also extracted using AccuPrep Genomic DNA extraction kit (i-genomic Blood DNA Extraction Mini Kit, Intron, Republic of Korea).

\section{DLA-DRB1 genotyping}

The second exon of DLA-DRB1 locus (DLA-DRB1.2) was amplified by nested polymerase chain reaction (PCR) and used for high resolution melting analysis (HRM) [21]. The first PCR step was performed in a final volume of $25 \mu \mathrm{L}$ containing $20 \mathrm{ng}$ genomic DNA, $1.5 \mathrm{mM} \mathrm{Mgcl}_{2}, 200 \mu \mathrm{M}$ of each dNTP, PCR buffer

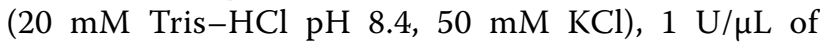
Taq DNA polymerase (CinaClon, Iran), and $20 \mathrm{pmol}$ of DRBF (5'-GATCCCCCCGTCCCCACAG-3') and DRBR3 (5'-CGCCCGCTGCGCTCA-3') primers, resulted in the amplification of $303 \mathrm{bp}$ DNA fragment. The thermal cycling profile for the first round of PCR was: 1 cycle of $95^{\circ} \mathrm{C}$ for $2 \mathrm{~min}, 15$ touch-down cycles of $95^{\circ} \mathrm{C}$ for $30 \mathrm{~s}$, followed by $30 \mathrm{~s}$ annealing, starting at $65.3^{\circ} \mathrm{C}$ and reducing by $0.5^{\circ} \mathrm{C}$ each cycle and $72{ }^{\circ} \mathrm{C}$ for $30 \mathrm{~s}$. Subsequently, $1 \mu \mathrm{L}$ of the first round PCR products was used as template DNA for the second round PCR in a final volume of $25 \mu \mathrm{L}$ containing 20 pmol of DRBTF (5'-CCCCCGTCCCCACAG-3') and DRBTR1 (5'-CCCCCACGTCGCTGTC-3') primers, resulted in the amplification of 138 bp DNA fragment. For HRM analysis, $1 \mu \mathrm{L}$ of EvaGreen ${ }^{\circledR}$ Dye $(2.5 \mathrm{mM})$ (Biotium, Darmstadt, Germany) was added to second step PCR master mix. The thermal cycling profile for the second round of PCR was: 1 cycle of $95^{\circ} \mathrm{C}$ for $2 \mathrm{~min}, 30$ cycles of $95^{\circ} \mathrm{C}$ for $30 \mathrm{~s}, 59.8^{\circ} \mathrm{C}$ for $30 \mathrm{~s}$ and $72{ }^{\circ} \mathrm{C}$ for $20 \mathrm{~s}$, and a final extension of $72{ }^{\circ} \mathrm{C}$ for $5 \mathrm{~min} .5 \mu \mathrm{L}$ of the last PCR stage was electrophoresed on $2 \%$ agarose gels in order 


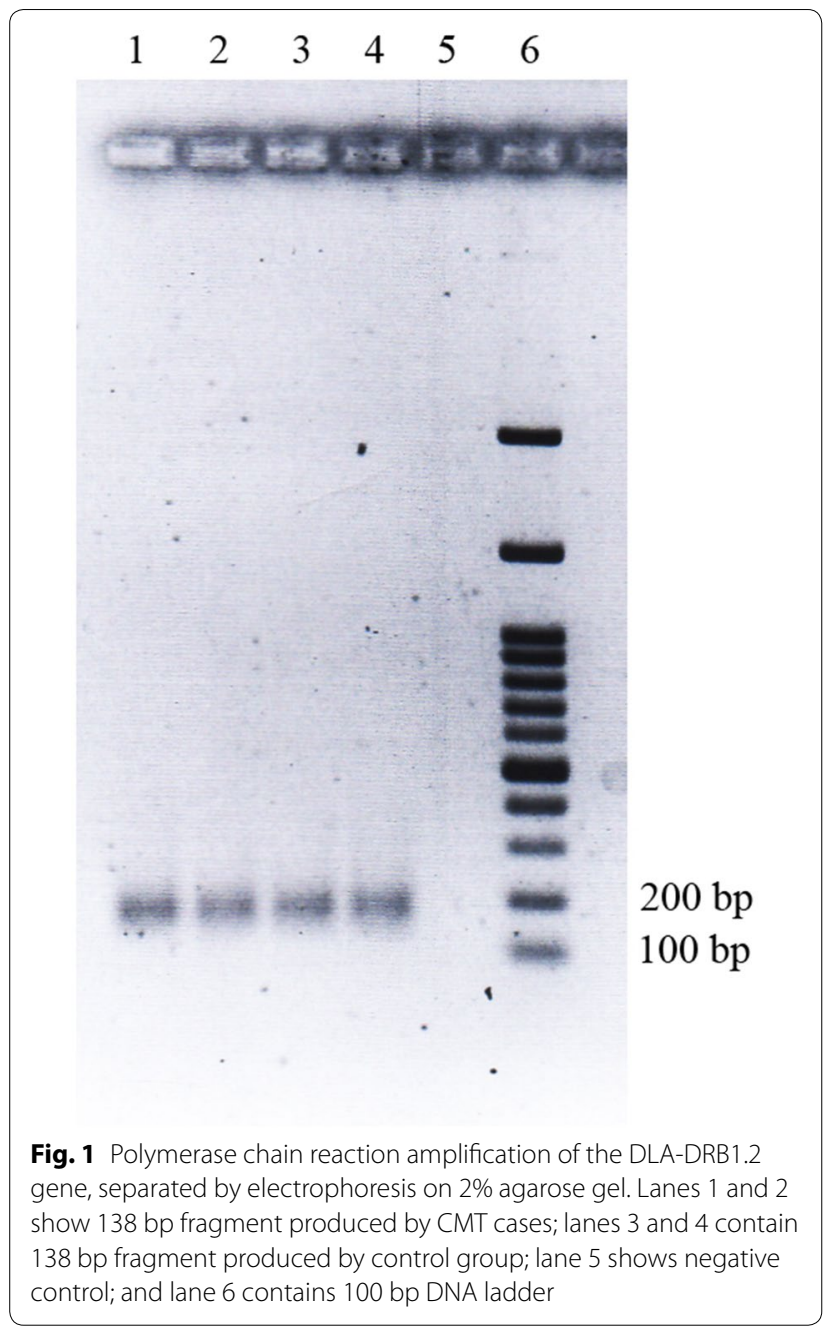

to check the quality and specificity of DNA fragment amplification (Fig. 1).

\section{High-resolution melting and melt curve analysis}

HRM and melt curve analysis was performed in a RotorGene $^{\mathrm{TM}} 6000$ thermal cycler (Corbett Life Science Pty Ltd, Sydney, Australia). In order to determine the optimal melting condition for differentiation of DLA-DRB1 alleles, the PCR products were setup on $0.2^{\circ} \mathrm{C} / \mathrm{s}$ ramping between 50 and $95{ }^{\circ} \mathrm{C}$. The melting profiles were analyzed using Rotor-Gene 1.7 software and the HRM algorithm provided. Identical graphs classified in same groups with $90 \%$ confidence percentage. Homozygosity or heterozygosity was characterized by presence of one or two thermal picks and confirmed by the graphs of HRM.

\section{Sequencing}

One sample from each HRM profile was sequenced to confirm the HRM results. Purification of PCR products and sequencing was performed by Macrogen Inc. (Seoul,
Republic of Korea) on an ABI 3730 XL automatic DNA sequencer (Applied Biosystems, Canada). Sequences were aligned using BioEdit software v7.2.0 and compared with other DLA-DRB1 sequences from IPD database (http://www.ebi.ac.uk/ipd/mhc/dla/index.html).

\section{Statistical analysis}

The effective allele numbers, genotype and allele frequencies, observed and expected homozygosity and heterozygosity for DLA-DRB1 locus were estimated using Popgene software [22]. The association between the DLA-DRB1 genotype and CMT profiles was determined as the odds ratio (OR). Frequency distribution of the genotype in each profile was compared using a general Chi squared test to examine the contribution of each genotype to the total Chi squared value. For genotype with a low or zero frequency, the denominator would be zero. In these cases, the OR would be undefined and Haldane`s modified Woolf formula was used for OR. The Fisher's exact test was done to determine if the OR was statistically significant or not. An odds ratio value higher than 1.0 indicated that those dogs carrying the genotype were at lower risk of developing the CMT and were considered resistant to tumor. An odds ratio lower than 1.0 showed that those dogs carrying that genotype were at increased risk of developing CMT and were considered susceptible. Data were analyzed using the SPSS software version 21 and probability of $\mathrm{P}<0.05$ was considered statistically significant (SPSS Institute, Chicago, IL, USA).

\section{Results}

\section{DLA-DRB1.2 genotyping}

HRM and melt curve analysis demonstrated eight patterns (A-H) in the 40 dogs (Fig. 2). The distribution of the DLA-DRB1.2 genotype frequencies related to each pattern is shown in Table 2. Genotype E showed the highest (22.2\%) and genotype $\mathrm{H}$ the lowest (5.6\%) frequency in the CMT group. In the control group, genotype A was the most (36.4\%) and genotypes B and D the least (4.5\%) frequent patterns, respectively (Table 2). Homozygote and heterozygote patterns identified through HRM analysis were confirmed by sequencing (Fig. 3). The observed heterozygosity (95.5) of DLA-DRB1.2 loci was significantly greater than the observed homozygosity (4.5\%) in the control group $(\mathrm{P} \leq 0.01)$. Results from the current study also revealed high level of heterozygosity in the tumor group, in which the proportion of heterozygous individuals was $66.7 \%$ (Fig. 4).

\section{Association of DLA-DRB1.2 genotypes with CMT profiles}

No significant association was observed between the DLA-DRB1.2 genotypes and type of CMT $(P>0.05)$ (Table 2). However, the association study revealed a 


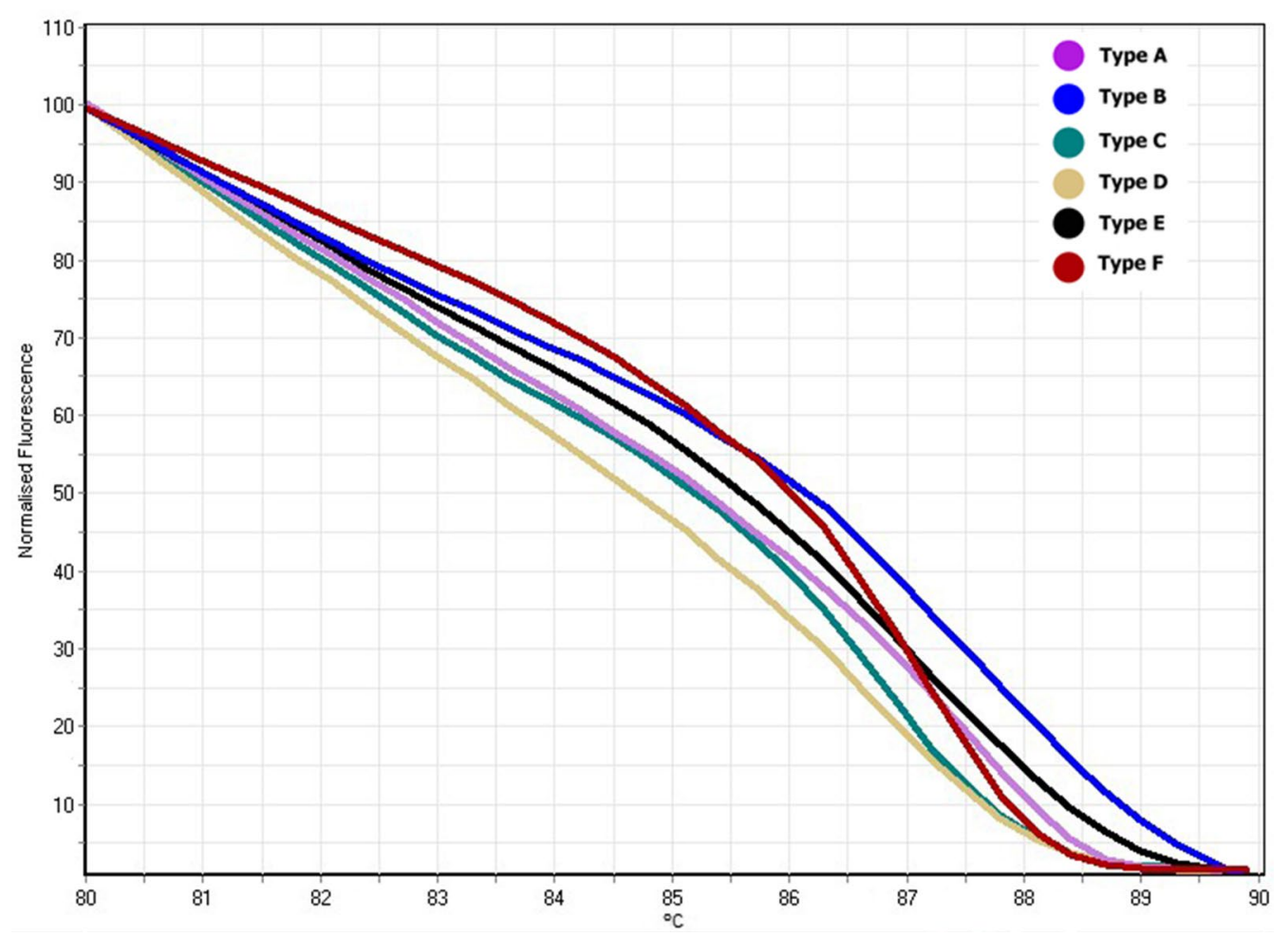

Fig. 2 DLA-DRB1.2 HRM profiles and alignment of genotype sequences

Table 2 DLA-DRB1 genotype frequencies and significant association of DLA genotypes and canine mammary tumor (CMT) between CMT cases and healthy controls

\begin{tabular}{lllll}
\hline $\begin{array}{l}\text { DLA-DRB1 } \\
\text { genotype }\end{array}$ & CMT $(\mathbf{n = 1 8 )}$ & Controls $(\mathbf{n = 2 2 )})$ & $\begin{array}{l}\text { Odds ratio } \\
(\mathbf{9 5 \%} \mathbf{C l})\end{array}$ & P-value \\
\hline A & $2(11.1 \%)$ & $8(36.4 \%)$ & 0.219 & 0.069 \\
B & $3(16.7 \%)$ & $1(4.5 \%)$ & 4.2 & 0.23 \\
C & $3(16.7 \%)$ & $3(13.6 \%)$ & 1.267 & 0.565 \\
D & $1(5.6 \%)$ & $1(4.5 \%)$ & 1.235 & 0.704 \\
E & $4(22.2 \%)$ & $2(9.1 \%)$ & 2.857 & 0.238 \\
F & $2(11.1 \%)$ & $3(13.6 \%)$ & 0.792 & 0.598 \\
G & $2(11.1 \%)$ & $2(9.1 \%)$ & 1.25 & 0.617 \\
H & $1(5.6 \%)$ & $2(9.1 \%)$ & 0.588 & 0.577 \\
\hline
\end{tabular}

significant correlation between DLA-DRB1.2 genotypes with different CMT profiles. The E genotype was significantly associated with increased risk of having a carcinoma arising in a benign tumor with high significant relationship $(\mathrm{P}=0.008 ; \mathrm{OR}=0.030)$ and $\mathrm{B}$ genotype represented a positive correlation with complex carcinoma $(P=0.013 ; O R=0.04)$ (Table 3$)$. Statistical analysis also revealed a significant association between the heterozygosity of DLA-DRB1.2 genotypes and presence of a CMT. DLA-DRB1.2 heterozygote genotypes were associated with lower risk of having a CMT $(\mathrm{P}=0.024$; $\mathrm{OR}=10.526$ ), while dogs with homozygote genotypes may develop mammary gland tumors more frequently. Association analysis between dog breed and CMT profiles indicated that the Terrier breed was more susceptible to development of a simple carcinoma mammary gland tumor $(\mathrm{P}=0.042$; $\mathrm{OR}=0.789)$ than other breeds.

\section{Discussion}

Mammary gland tumors are the most common tumor in bitches with the incidence rate of about $25 \%$. Among different factors involved in the development of CMTs, genetic background plays the leading role and can be considered as an expedient approach for early diagnosis of tumor and planning strategies towards having resistant populations [23]. However, selection based on genetics with a view of improving immunity and disease resistance needs powerful genetic markers linked to the immune system [24]. MHC class I molecules present endogenous antigens such as tumor peptides to cytotoxic $\mathrm{T}$ lymphocytes and mediate cellular immunity against tumor development $[12,25]$. On the other side, class II molecules present exogenous antigens to helper $\mathrm{T}$ lymphocytes and induce humoral immune responses. Evidences suggest that MHC class II genes may play an important role in developing the risk of different tumors 


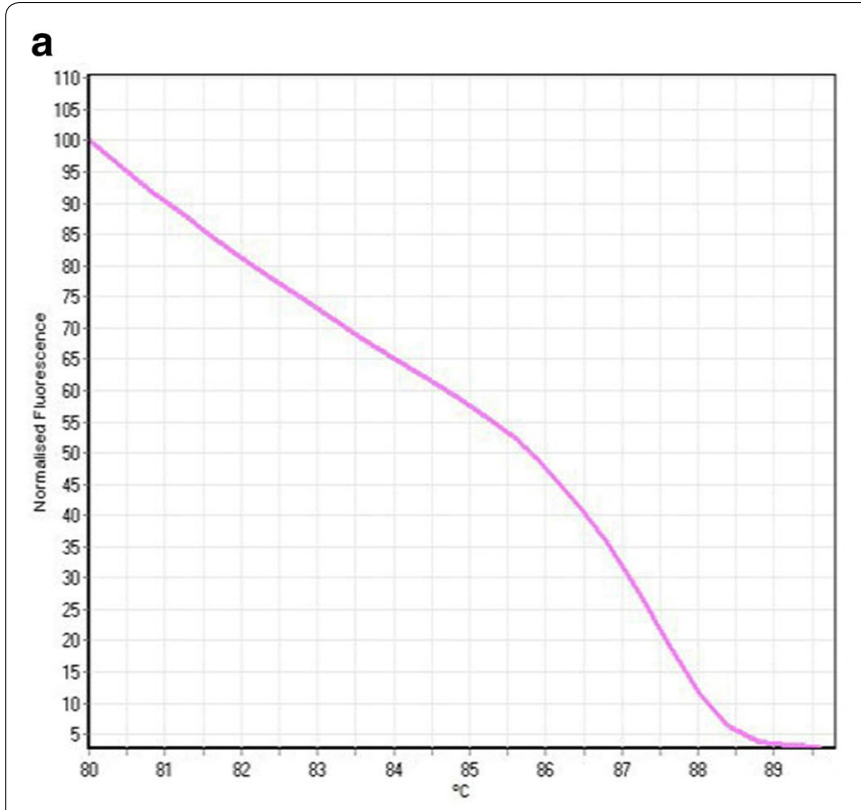

G GCT T C T G GT GA GA

\section{b}

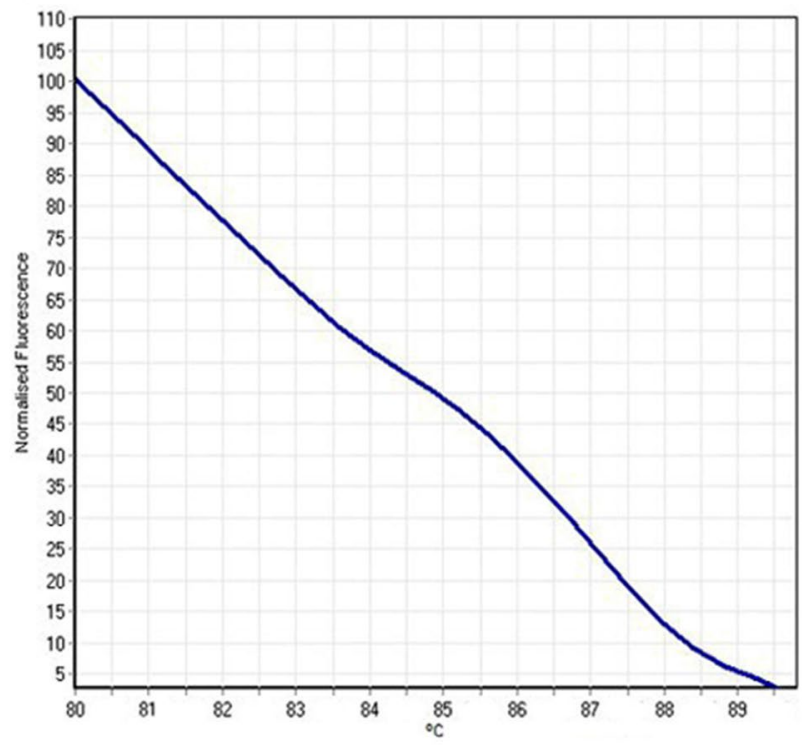

G GY TK S T G G WRA GA

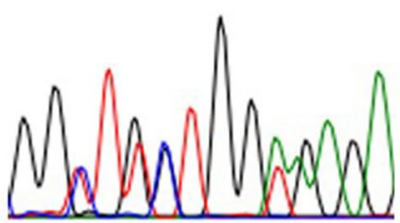

Fig. 3 Confirmation of HRM profiles through sequencing in two homozygote (a) and heterozygote (b) samples

including cutaneous $\mathrm{T}$ cell lymphoma [26], renal cell carcinoma [11], breast cancer [19, 27], melanoma [13], acute leukemia [14], cervical cancer [15], and colorectal carcinoma [16] and any changes to the molecular structure of this class could be related to these neoplasms. Nevertheless, it is unclear that MHC II alleles in themselves have a causative effect on the development of tumors or whether they are the markers showing indirect association with the causative genes located in their vicinity and are in linkage disequilibrium with them.

MHC class II genes are appropriate candidates for studying the molecular genetic factors that may be associated with development of CMTs in different populations $[12,17-19,27]$. In the current study, we report the DLA-DRB1.2 polymorphism in a dog population and its association with mammary gland tumor profiles. DLA genetic diversity was evaluated using HRM technique and DNA sequencing method. In total, eight HRM patterns with a high level of heterozygosity were identified. Sequencing data also confirmed the HRM results regarding the homozygosity and heterozygosity of genotypes. HRM technique has been applied successfully for HLA genotyping in recent years [28-30]. Results of this study also propose that HRM technique could be considered as an appropriate MHC genotyping method in dogs, particularly when combined with DNA sequencing. HRM is able to identify homozygote or heterozygote genotypes in a fast, reliable and inexpensive way. However, more accurate and powerful approaches such as sequencing might be complementary to confirm the exact alleles.

The association study revealed a significant correlation between DLA-DRB1.2 genotypes E and B with susceptibility to the CMT profiles including carcinomas arising in a benign tumor and complex carcinomas. DLA class II loci have been associated with a number of canine autoimmune diseases including pancreatic acinar atrophy [31], hypoadrenocorticism (Addison's disease) [32], CSK [9], necrotising meningoencephalitis [33], systemic lupus erythromatosus-related diseases [7], immune-mediated hemolytic anemia [5] and anal furunculosis [34]. Association of DLA loci with tumor development has been estimated but to a limited extent. Aguirre-Hernández et al. [35] studied the association between anal sac gland carcinoma with MHC class II loci (DLA-DRB1, DLADQA1, DLA-DQB1) in English Cocker Spaniels and showed significant correlations. The DLA-DQB1*00701 


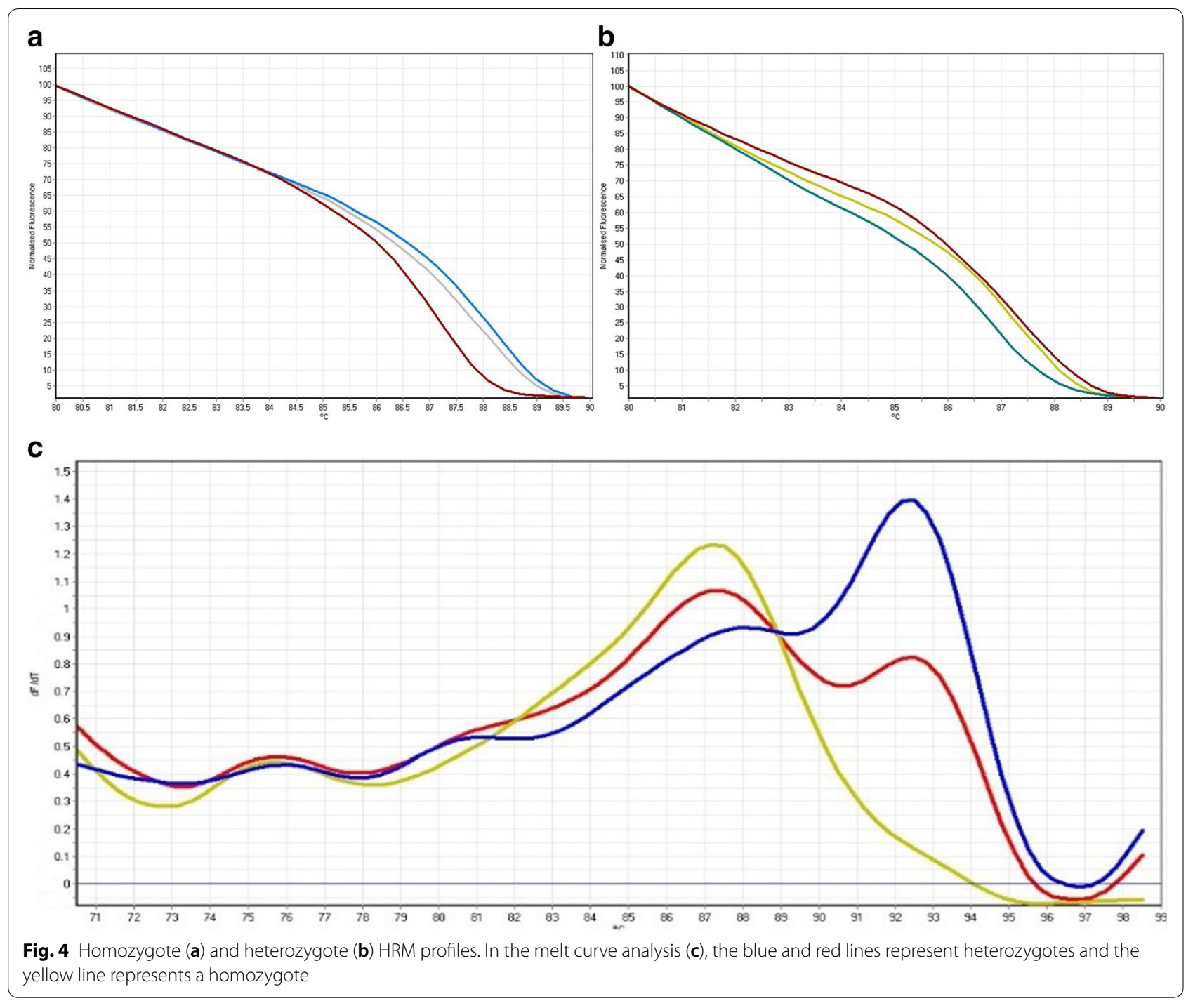

Table 3 Association of DLA-DRB1.2 genotypes with canine mammary tumor (CMT) profiles

\begin{tabular}{|c|c|c|c|c|c|c|c|c|}
\hline \multirow[t]{2}{*}{ CMT profiles } & \multicolumn{4}{|c|}{ Fisher's exact test (P-value) } & \multicolumn{4}{|c|}{ Odds ratio $(95 \% \mathrm{Cl})$} \\
\hline & $\begin{array}{l}\text { Complex } \\
\text { carcinoma }\end{array}$ & $\begin{array}{l}\text { Simple } \\
\text { carcinoma }\end{array}$ & $\begin{array}{l}\text { Carcinomas } \\
\text { in benign } \\
\text { tumor }\end{array}$ & $\begin{array}{l}\text { Special types } \\
\text { of carcinomas }\end{array}$ & $\begin{array}{l}\text { Complex } \\
\text { carcinoma }\end{array}$ & $\begin{array}{l}\text { Simple } \\
\text { carcinoma }\end{array}$ & $\begin{array}{l}\text { Carcinomas } \\
\text { in benign } \\
\text { tumor }\end{array}$ & $\begin{array}{l}\text { Special types } \\
\text { of carcinomas }\end{array}$ \\
\hline A & 0.428 & 0.744 & 0.300 & 0.558 & 2.252 & 1.000 & 1.153 & 1.071 \\
\hline B & 0.013 & 0.645 & 0.645 & 0.808 & 0.041 & 1.124 & 1.124 & 1.059 \\
\hline C & 0.721 & 0.100 & 0.507 & 0.719 & 1.071 & 0.125 & 1.133 & 1.062 \\
\hline $\mathrm{D}$ & 0.677 & 0.808 & 0.192 & 0.901 & 1.225 & 1.117 & 0.085 & 1.055 \\
\hline$E$ & 0.721 & 0.507 & 0.008 & 0.719 & 1.071 & 1.113 & 0.030 & 1.062 \\
\hline $\mathrm{F}$ & 0.361 & 0.427 & 0.573 & 0.237 & 1.250 & 0.374 & 1.128 & 0.117 \\
\hline G & 0.552 & 0.645 & 0.645 & 0.192 & 0.599 & 1.124 & 1.124 & 0.085 \\
\hline $\mathrm{H}$ & 0.552 & 0.723 & 0.723 & 0.854 & 1.233 & 1.121 & 1.121 & 1.057 \\
\hline
\end{tabular}


allele was associated with susceptibility for developing the carcinoma, while allele DLA-DQB1*02001 was resistant. DLA-DRB1 allele frequency showed no significant differences between cases and controls. In spite of the confirmed role of inflammatory responses in development of CMTs [36], there is no information regarding the MHC class II genotypes and CMT resistance. Therefore, the present study may highlight the significance of MHC molecules in developing carcinomas arising in a benign tumor and complex carcinomas.

The data revealed that DLA-DRB1.2 homozygote genotypes may have the higher risk of developing CMTs. These results are in agreement with a previous study, which reported that homozygosity in MHC class II genes increased the risk for developing CSK. Barrientos et al. [9] showed that dogs homozygous for the DLA-DRB1*69 allele had a risk for developing CSK that was over four times the risk of heterozygotes [9]. Dobermans with homozygous DLA-DRB1*00601, DLA-DQA1*00401 and DLA-DQB1*01303 genotypes were also more susceptible to Doberman hepatitis [37]. According to the heterozygosity advantage theory, homozygosity at MHC genes restricts the host's ability to present a wider repertoire of immunogenic peptides to the immune system and leads to inefficient immune responses that increase the risk of tumor.

Considering the association between dog breeds and risk of having a CMT, no significant correlation was observed in this study. Salas et al. [38] revealed that Poodle, Cocker Spaniel, German Shepherd and Labrador Retriever were the most popular breeds affected by CMTs [38]. In another study conducted on occurrence and distribution of neoplasms in dogs, CMTs were reported in Poodle, Maltese, Chihuahua, Beagle, Yorkshire Terrier, Bichon Frisé, Cocker spaniel, English Springer Spaniel, Setter, Hound and German Shepherd breeds [39].

\section{Conclusions}

The possible role of DLA-DRB1 gene polymorphism in developing CMT is reported. Statistically significant differences were observed in the distribution of DLA-DRB1 genotypes between different CMT profiles. The two most common genotypes in the tumor group ( $E$ and $B$ ) were associated with carcinomas arising in a benign tumor and complex carcinoma profiles, respectively. Findings of this study provide additional support for the association between MHC class II genes and development of CMT. Although this association can primarily explain the genetic basis of CMT, other susceptibility genes may also contribute to the development of these kind of tumors and need to be further examined. These results could potentially be used for early recognition of an increased risk of developing CMT and identifying susceptible dogs that require monitoring. However, it is worth noting that conclusions were made from a hypothesis generating study and more confirmatory studies needed.

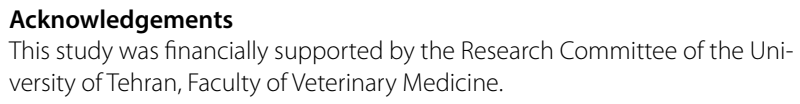

Prior publication

Data have not been published previously.

\section{Authors' contributions}

GN, SMV and SJ presented the idea of the study and designed the study. SMV and LL coordinated and performed the sampling. SMV, GN and LL were in charge of the laboratory analyses. GN analysed the data. SMV, NA and AE drafted the manuscript. All authors read and approved the final manuscript.

\section{Funding}

This study was funded by University of Tehran.

\section{Availability of data and materials}

The datasets used and/or analysed during the current study are available from the corresponding author on reasonable request.

\section{Ethics approval and consent to participate}

The study was approved by Institutional Ethical Committee of University of Tehran, Tehran, Iran.The animals were handled according to high ethical standards and national legislation.

\section{Consent for publication}

Not applicable.

\section{Competing interests}

The authors declare that they have no competing interests.

\section{Author details}

${ }^{1}$ Department of Microbiology and Immunology, Faculty of Veterinary Medicine, University of Tehran, Tehran, Islamic Republic of Iran. ${ }^{2}$ Department of Internal Medicine, Faculty of Veterinary Medicine, University of Tehran, Tehran, Islamic Republic of Iran. ${ }^{3}$ Department of Pathobiology, School of Veterinary Medicine, Shiraz University, Shiraz, Islamic Republic of Iran.

Received: 21 February 2019 Accepted: 4 November 2019

Published online: 14 November 2019

\section{References}

1. MacEwen EG. Spontaneous tumors in dogs and cats: models for the study of cancer biology and treatment. Cancer Metast Rev Cancer Metastasis Rev. 1990;9:125-36.

2. Sleeckx N, de Rooster H, Veldhuis Kroeze E, Van Ginneken C, Van Brantegem L. Canine mammary tumours, an overview. Reprod Dom Anim. 2011:46:1112-31.

3. Rivera P, Melin M, Biagi T, Fall T, Häggström J, Lindblad-Toh K, et al. Mammary tumor development in dogs is associated with BRCA1 and BRCA2. Cancer Res. 2009;69:8770-4.

4. Wagner JL. Molecular organization of the canine major histocompatibility complex. J Hered. 2003;94:23-6.

5. Kennedy LJ, Barnes A, Ollier WE, Day MJ. Association of a common dog leucocyte antigen class II haplotype with canine primary immune-mediated haemolytic anaemia. Tissue Antigens. 2006;68:502-8.

6. Kennedy LJ, Barnes A, Short A, Brown JJ, Lester S, Seddon J, et al. Canine DLA diversity: 1. New alleles and haplotypes. Tissue Antigens. 2007;69:272-88.

7. Wilbe M, Jokinen P, Hermanrud C, Kennedy LJ, Strandberg E, HanssonHamlin $\mathrm{H}$, et al. MHC class II polymorphism is associated with a canine SLE-related disease complex. Immunogenetics. 2009;61:557-64. 
8. Hughes AM, Jokinen P, Bannasch DL, Lohi H, Oberbauer AM. Association of a dog leukocyte antigen class II haplotype with hypoadrenocorticism in Nova Scotia Duck Tolling Retrievers. Tissue Antigens. 2010;75:684-90.

9. Barrientos LS, Zapata G, Crespi JA, Posik DM, Díaz S, It V, et al. A study of the association between chronic superficial keratitis and polymorphisms in the upstream regulatory regions of the DLA-DRB1, DLA-DQB1 and DLA-DQA1. Vet Immunol Immunopathol. 2013;156:205-10.

10. Shiel RE, Kennedy LJ, Nolan CM, Mooney CT, Callanan JJ. Major histocompatibility complex class II alleles and haplotypes associated with non-suppurative meningoencephalitis in greyhounds. Tissue Antigens. 2014;84:271-6.

11. Kojima Y, Takahara S, Nonomura N, Sada M, Tsuji T, Hatori M, et al. HLADRB genotypes in Japanese patients with renal cell carcinoma. Oncology. 2000;59:57-62.

12. Ghaderi A, Talebi A, Gharesifard B, Farjadian SH, Amirzargar A, Vasei M. HLA-DRB 1 Alleles and the susceptibility of Iranian patients with breast cancer. Pathol Oncol. 2001;7:39-41.

13. Planelles D, Nagore E, Moret A, Botella-Estrada R, Vila E, Guillén C, et al. HLA class II polymorphisms in Spanish melanoma patients: homozygosity for HLA-DQA1 locus can be a potential melanoma risk factor. Br J Dermatol. 2006;154:261-6.

14. Uçar F, Sönmez M, Erkut N, Balcı M, Yücel B, Yılmaz M, et al. Relation of HLA-A, -B, -DRB1 alleles and haplotypes in patients with acute leukemia: a case control study. Arch Med Res. 2011;42:305-10.

15. Wei LZ, Wang HL, Liu X, Lu YP, Xu F, Yuan JQ, et al. Meta-analysis on the relationship between HLA-DRBI gene polymorphism and cervical cancer in Chinese population. PLoS ONE. 2014;9:e88439.

16. Aureli A, Canossi A, Del Beato T, Franceschilli L, Buonomo O, Papola F, et al. HLA-DRB1*13:01 allele in the genetic susceptibility to colorectal carcinoma. Int J Cancer. 2015;136:2464-8.

17. Chaudhuri S, Cariappa A, Tang M, Bell D, Haber DA, Isselbacher KJ, et al. Genetic susceptibility to breast cancer: HLA DQB*03032 and HLA DRB1*11 may represent protective alleles. PNAS. 2000;97:11451-4.

18. Harrath AB, Loueslati BY, Troudi W, Hmida S, Sedkaoui S, Dridi A, et al. HLA class II polymorphism: protective or risk factors to breast cancer in Tunisia? Pathol Oncol Res. 2006;12:79-81.

19. Cantú León DC, Pérez-Montiel D, Villavicencio V, García Carranca A, Mohar Betancourt A, Acuña-Alonzo V, et al. High resolution human leukocyte antigen (HLA) class I and class II allele typing in Mexican mestizo women with sporadic breast cancer: case-control study. BMC Cancer. 2009;9:48.

20. Misdorp W, Else RW, Hellmen E, Lipscomb TP. Histologic classification of mammary tumors of the dog and the Cat, 2nd series. AFIP. 1999:7:1-59.

21. Vahedi SM, Jamshidl Sh, Lankarani Mohajer L, Nikbakht Brujeni Gh. Discrimination of dog MHC (DLA-DRB1) alleles by high-resolution melt analysis. J Vet Res. 2018;73:93-100.

22. Yeh FC, Boyle TJB. Population genetic analysis of codominant and dominant markers and quantitative traits. Belg J Bot. 1997;130:129-57.

23. Sorenmo KU, Worley DR, Goldschmidt MH. Tumors of the Mammary Gland. In: Withrow SJ, Vail DM, Page RL, editors. Withrow and MacEwen's small animal clinical oncology. Missouri: Saunders; 2013. p. 538-56.

24. Esteban EN, Poli M, Poiesz B, Ceriani C, Dube S, Gutierrez S, et al. Bovine leukemia virus (BLV), proposed control and eradication programs by marker assisted breeding of genetically resistant cattle. In: Animal genetics. 2009. p. 107-30.
25. Lin Z, Xin Y, Dong Q, Wang Q, Jiang XJ, Zhan SH, et al. Association between HLA-DRB1 alleles polymorphism and hepatocellular carcinoma: a meta-analysis. BMC Gastroenterol. 2010;10:145.

26. Jackow CM, McHam JB, Friss A, Alvear J, Reveille JR, Duvic M. HLA-DR5 and DQB $1{ }^{*} 03$ class II alleles are associated with cutaneous T-cell lymphoma. J Invest Dermatol. 1996;107:373-6.

27. Yang XX, Pan HZ, Li PY, Li FX, Xu WW, Wu YS, et al. HLA class II variants in Chinese breast cancer patients. Asian Pacific J Cancer Prev. 2011;12:3075-9.

28. Yu B, Chen Y, Wu Q, Li P, Shao Y, Zhang J, et al. The association between single-nucleotide polymorphisms of NCF2 and systemic lupus erythematosus in Chinese mainland population. Clin Rheumatol. 2011;30:521-7.

29. Lundgren A, Kim S, Stadnisky MD, Brown MG. Rapid discrimination of MHC class I and killer cell lectin-like receptor allele variants by highresolution melt analysis. Immunogenetics. 2012;64:633-40.

30. Cui G, Zhang L, Xu Y, Cianflone K, Ding H, Wang DW. Development of a high resolution melting method for genotyping of risk HLA-DQA1 and PLA2R1 alleles and ethnic distribution of these risk alleles. Gene. 2013;514:125-30

31. Tsai KL, Starr-Moss AN, Venkataraman GM, Robinson C, Kennedy LJ, Steiner JM, et al. Alleles of the major histocompatibility complex play a role in the pathogenesis of pancreatic acinar atrophy in dogs. Immunogenetics. 2013;65:501-9.

32. Massey J, Boag A, Short AD, Scholey RA, Henthorn PS, Littman MP, et al. MHC class II association study in eight breeds of dog with hypoadrenocorticism. Immunogenetics. 2013;65:291-7.

33. Greer KA, Wong AK, Liu H, Famula TR, Pedersen NC, Ruhe A, et al. Necrotizing meningoencephalitis of pug dogs associates with dog leukocyte antigen class $I$ and resembles acute variant forms of multiple sclerosis. Tissue Antigens. 2010;76:110-8.

34. Barnes A, O'Neill T, Kennedy LJ, Short AD, Catchpole B, House A, et al. Association of canine anal furunculosis with TNFA is secondary to linkage disequilibrium with DLA-DRB1*. Tissue Antigens. 2009;73:218-24.

35. Aguirre-Hernández J, Polton G, Kennedy LJ, Sargan DR. Association between anal sac gland carcinoma and dog leukocyte antigen-DQB1 in the English Cocker Spaniel. Tissue Antigens. 2010;76:476-81.

36. Rutten VP, Misdorp W, Gauthier A, Estrada M, Mialot JP, Parodi AL, et al. Immunological aspects of mammary tumors in dogs and cats: a survey including own studies and pertinent literature. Vet Immunol Immunopathol. 1990;26:211-25.

37. Dyggve H, Kennedy LJ, Meri S, Spillmann T, Lohi H, Speeti M. Association of Doberman hepatitis to canine major histocompatibility complex II. Tissue Antigens. 2011;77:30-5.

38. Salas $Y$, Márquez A, Diaz D, Romero L. Epidemiological study of mammary tumors in female dogs diagnosed during the period 2002-2012: a growing animal health problem. PLoS ONE. 2015;10:e0127381.

39. Bronden LB, Nielsen SS, Toft N, Kristensen AT. Data from the Danish veterinary cancer registry on the occurrence and distribution of neoplasms in dogs in Denmark. Vet Rec. 2010;166:586-90.

\section{Publisher's Note}

Springer Nature remains neutral with regard to jurisdictional claims in published maps and institutional affiliations.

\footnotetext{
Ready to submit your research? Choose BMC and benefit from:

- fast, convenient online submission

- thorough peer review by experienced researchers in your field

- rapid publication on acceptance

- support for research data, including large and complex data types

- gold Open Access which fosters wider collaboration and increased citations

- maximum visibility for your research: over 100M website views per year
}

At BMC, research is always in progress.

Learn more biomedcentral.com/submissions 